\title{
Erratum to: Towards user empowerment in product design: a mixed reality tool for interactive virtual prototyping
}

Pierre-Antoine Arrighi ${ }^{1}$ (D) C Céline Mougenot ${ }^{1}$

Published online: 24 May 2017

(C) Springer Science+Business Media New York 2017

\section{Erratum to: J Intell Manuf DOI 10.1007/s10845-016-1276-0}

The Acknowledgements section was not included in the original publication of the article. It is published with this erratum.
Acknowledgements This research is supported by KAKENHI Grant Number 15K16167 from the Japan Society for the Promotion of Science (JSPS).
The online version of the original article can be found under https:// doi.org/10.1007/s10845-016-1276-0.

$\triangle$ Pierre-Antoine Arrighi pa.arrighi@gmail.com

1 School of Engineering, Tokyo Institute of Technology, 2-12-1 i6-22 Ookayama, Meguro-ku, Tokyo 152-8550, Japan 